\title{
Einvernehmliche Streitbeilegung internationaler Wirtschaftsstreitigkeiten unter den ADR-Regeln der Internationalen Handelskammer (ICC)
}

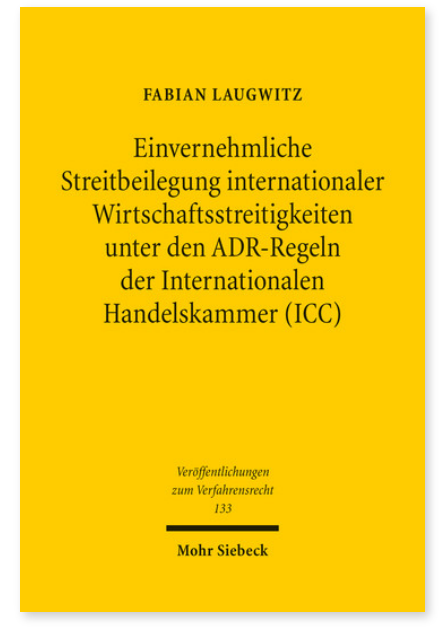

2016. XIX, 328 Seiten. VVerfR 133

ISBN 978-3-16-154830-7

DOI 10.1628/978-3-16-154830-7

eBook PDF 94,00€

ISBN 978-3-16-154667-9

fadengeheftete Broschur 94,00€
Dem international Handeltreibenden steht inzwischen eine Fülle verschiedenster Verfahrensordnungen zur Verfügung, um grenzüberschreitenden Wirtschaftsstreitigkeiten im Wege einvernehmlicher Streitbeilegung zu begegnen.

Fabian Laugwitz beleuchtet mit den ADR-Regeln (Amicable Dispute Resolution) der Internationalen Handelskammer eines dieser Regelwerke. Die Untersuchung erstreckt sich dabei nicht nur auf die ICC-ADR-Regeln und deren Wirkung in einzelnen Rechtsordnungen, sondern auch auf die Notwendigkeit und den nötigen Umfang eines Verfahrensrahmens für einvernehmliche Streitbeilegungsverfahren.

Fabian Laugwitz Geboren 1981; Studium der Rechtswissenschaften und Begleitstudium im Europäischen Recht an der JuliusMaximilians-Universität Würzburg; 2009 Erste Juristische Prüfung; Promotions- und Aufbaustudium des Europäischen Rechts (LL.M. Eur.), Wissenschaftlicher Mitarbeiter und Lehrbeauftragter im Bereich Fachsprachen und ausländisches Recht an der Julius-Maximilians-Universität Würzburg; Referendariat im OLG-Bezirk Frankfurt a. M. /LG Darmstadt mit Stationen in Frankfurt am Main und London; 2013 zweite juristische Staatsprüfung, seit 2013 Rechtsanwalt in Frankfurt a.M.; 2015 Promotion.

\section{Jetzt bestellen:}

https://mohrsiebeck.com/buch/einvernehmliche-streitbeilegung-internationaler-wirtschaftsstreitigkeiten-unter-den-adrregeln-der-internationalen-handelskammer-icc-9783161548307?no_cache=1

order@mohrsiebeck.com

Telefon: $+49(0) 7071-923-17$

Telefax: +49 (0)7071-51104 